le portiQue $\begin{array}{ll}\text { Le Portique } \\ \text { Revue de philosophie et de sciences humaines }\end{array}$

33 | 2014

Straub !

\title{
Autour de O Somma Luce et de Corneille
}

Jean-Marie Straub

\section{(2) OpenEdition}

\section{Journals}

\section{Electronic version}

URL: http://journals.openedition.org/leportique/2759

DOI: 10.4000/leportique.2759

ISSN: $1777-5280$

\section{Publisher}

Association "Les Amis du Portique"

Printed version

Date of publication: 1 May 2014

ISSN: 1283-8594

\section{Electronic reference}

Jean-Marie Straub, "Autour de O Somma Luce et de Corneille", Le Portique [Online], 33 | 2014, document 2, Online since 05 February 2016, connection on 12 April 2021. URL: http://

journals.openedition.org/leportique/2759; DOI: https://doi.org/10.4000/leportique.2759

This text was automatically generated on 12 April 2021.

Tous droits réservés 


\title{
Autour de O Somma Luce et de Corneille
}

\author{
Jean-Marie Straub
}

1 Bernard Muscat (Ciné Art) - Vous allez assister, ce soir, à une projection qui utilise un vidéoprojecteur numérique... Depuis le début de la rétrospective, le vidéoprojecteur a servi à projeter des films qui étaient sur des supports qui s'appellent des cassettes DigiBéta, c'est-à-dire de la vidéo numérique. Mais là, dans le cas de $\mathrm{O}$ Somma Luce c'est tout à fait particulier : il s'agit d'un fichier numérique qui est sur un disque dur externe, qu'on est allé chercher dans une société qui est à Bayon, à $90 \mathrm{~km}$ d'ici, une entreprise de transports qui distribue des films sur pellicule depuis 55 ans. Et il y a sept salariés, cinq camionnettes. Ils distribuent des films depuis Paris dans toute la Lorraine, dans tout l'est de la France. C'est grâce à eux que les films, depuis des années, ont pu être projetés dans les cinémas de Lorraine. Et la gérante, qui a 78 ans, m'a dit qu'ils étaient inquiets parce qu'ils n'auraient bientôt plus de films à transporter, ou bien de tout petits paquets. Que, sans doute, le marché leur échappera, qu'il sera donné à d'autres sociétés... Il faut qu'ils se reconvertissent, sinon la société va couler. Je voulais vous le dire, parce qu'on assiste à une projection qui sera, sans doute, très bonne techniquement mais qui nous fait passer dans un autre monde... Jean-Marie?

2 Jean-Marie Straub - Alors, ces deux films, contrairement au Kafka, qui était un film hollywoodien, hawksien même (je parle d'Howard Hawks), peut-être que ce n'est pas des films. En tout cas, j'espère que ce n'est pas des films. Voilà.

L'histoire, dans les deux cas, ce n'est pas compliqué, c'est déjà une décadence... 0 Somma Luce, c'est le seul film que, par hasard, toujours par hasard, on a tourné avec une caméra qui s'appelle la Red, qui est une caméra numérique sophistiquée, qui pratique image par image et non par défilement continu. Cette caméra-là, si on projette ce qu'on a tourné, ça s'appelle $4 \mathrm{~K}$. Désolé, ce n'est pas moi qui ai inventé tout ça. Or, ici, déjà, on va projeter en $2 \mathrm{~K}$, et à Paris, ça a été projeté en je ne sais pas quoi, comment ça s'appelle?

Barbara Ulrich - Digi Béta. 
J.-M. S. - Digi Béta. On fait un truc, et puis, après, on passe d'une décadence à l'autre... Ici, on est au milieu. Ça ne veut pas dire que ce soit bon. In medio stat virtus.

6 Bon alors l'autre film, vous n'êtes pas obligés de rester jusqu'au bout... ça sera en trois parties, mais ça sera toujours le même film. La première fois, vous aurez droit à des sous-titres. Ensuite, vous serez privés de sous-titres.

7 B. M. - Corneille-Brecht, vous l'avez tourné avec une caméra tout à fait basique. Ce n'est pas une caméra Haute Définition que vous avez utilisée, n'est-ce pas?

8 J.-M. S. - Non, c'est une caméra complètement amateur. C'est tout le contraire de l'autre film. Bon enfin, tout ça n'a d'importance, que pour l'artisanat...À part ça, le deuxième film, c'était pas prévu que ça soit un film. C'est pour ça que je vous ai dit que ce n'est peut-être pas un film. Il y a une jeune personne qui vit en France depuis très longtemps, qui est Bavaroise, et qui vit avec un musicien. Elle s'appelle Cornelia Geiser. Elle vit avec un musicien qui a un nom bien français, il s'appelle Bertrand Brouder. On a fait connaissance, il y a douze ans ; ils voyaient de temps en temps des films de nous. Et puis elle disait: «j'aimerais bien travailler un texte avec vous». Je n'ai jamais trouvé le temps, j'étais trop paresseux. Et puis, quand je me suis retrouvé cloué à l'hôpital, je lui ai proposé de travailler deux petits bouts de Corneille. Et puis, quand on avait fini de travailler ça, je me suis dit : « bon Dieu, cette pauvre femme, sa langue maternelle, c'est l'allemand, et je lui ai fait travailler un texte de Brecht qui n'est pas une pièce de théâtre, mais une pièce radiophonique. Et puis en la voyant travailler le texte, je me suis dit tout d'un coup: "tiens, on devrait filmer ça, ça pourrait faire une sorte de film ». Voilà. 